\title{
Consensus-based care recommendations for congenital and childhood-onset myotonic dystrophy type 1
}

Nicholas E. Johnson, MD, MSCl, Eugenio Zapata Aldana, MD, Nathalie Angeard, PhD, Tetsuo Ashizawa, MD, Kiera N. Berggren, MA/CCC-SLP, MS, Chiara Marini-Bettolo, MD, PhD, Tina Duong, MPT, PhD, Anne-Berit Ekström, MD, PhD, Valeria Sansone, MD, Cuixia Tian, MD, Leah Hellerstein, LCSW, MPH, and Craig Campbell, MD, on behalf of the Myotonic Dystrophy Foundation

Neurology: Clinical Practice October 2019 vol. 9 no. 5 443-454 doi:10.1212/CPJ.0000000000000646
Correspondence

Leah Hellerstein, LCSW, MPH

Leah.Hellerstein@myotonic.org

\section{Abstract}

\section{Purpose of review}

Myotonic dystrophy type 1 is a multisystemic disorder caused by a noncoding triplet repeat. The age of onset is variable across the lifespan, but in its most severe form, the symptoms appear at birth (congenital myotonic dystrophy) or in the pediatric age range (childhood-onset myotonic dystrophy). These children have a range of disabilities that reduce the lifespan and cause significant morbidity. Currently, there are no agreed upon recommendations for caring for these children.

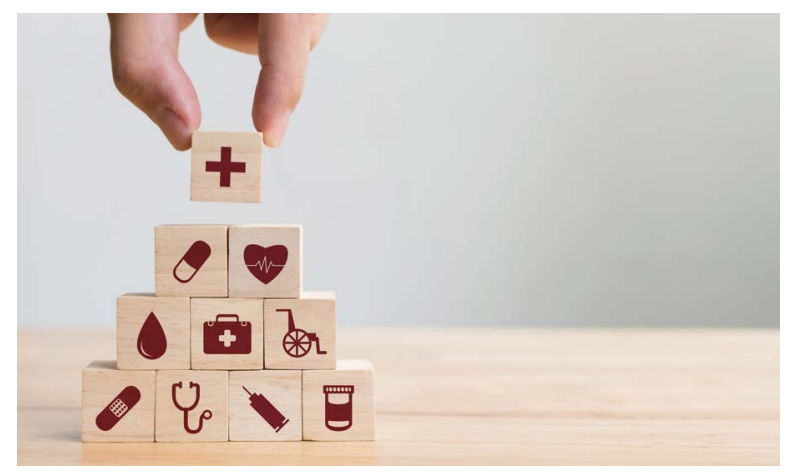

\section{Recent findings}

The Myotonic Dystrophy Foundation recruited 11 international clinicians who are experienced with congenital and childhood-onset myotonic dystrophy to create consensus-based care recommendations. The experts used a 2-step methodology using elements of the single text procedure and nominal group technique. Completion of this process has led to the development of clinical care recommendations for this population.

\section{Summary}

Children with myotonic dystrophy often require monitoring and interventions to improve the lifespan and quality of life. The resulting recommendations are intended to standardize and improve the care of children with myotonic dystrophy.

Myotonic dystrophy type 1 (DM1) is an autosomal dominant disorder caused by a toxic CTG repeat expansion in the $3^{\prime} \mathrm{UTR}$ of the DMPK gene. ${ }^{1-3}$ In adults with DM1, symptoms are characterized by progressive distal muscle weakness, myotonia, early onset cataracts, cardiac and gastrointestinal problems, and dysfunction in the CNS. ${ }^{4,5}$ The multiorgan involvement is often more pronounced and with earlier onset in individuals with symptom onset in childhood. The age of onset of DM1 is variable, and intergenerational repeat expansion (known as anticipation) may result in symptom onset during childhood. When symptom onset occurs at birth, this is known as congenital onset myotonic dystrophy (CDM). Symptom onset after the newborn period and up to

Virginia Commonwealth University (NEJ, KNB), Richmond, VA; University of Western Ontario (EZA, CC), Ontario, Canada; Inserm \& University of Paris Descartes (NA), France; Houston Methodist Neurological Institute (TA), TX; Institute of Genetic Medicine (CM-B), Newcastle University and Newcastle upon Tyne Hospitals NHS Foundation Trust, Newcastle upon Tyne, UK; Stanford University (TD), CA; Queen Silvia Children's Hospital (A-BE), Gothenburg, Sweden; NEMO Clinic (VS), Milan, Italy; Cincinnati Children's Hospital Medical Center (CT), OH; and Myotonic Dystrophy Foundation (LH), San Francisco, CA.

Funding information and disclosures are provided at the end of the article. Full disclosure form information provided by the authors is available with the full text of this article at Neurology.org/cp.

The Article Processing Charge was funded by the Myotonic Dystrophy Foundation.

This is an open access article distributed under the terms of the Creative Commons Attribution-NonCommercial-NoDerivatives License 4.0 (CC BY-NC-ND), which permits downloading and sharing the work provided it is properly cited. The work cannot be changed in any way or used commercially without permission from the journal. 
The age of onset of DM1 is variable, and intergenerational repeat expansion (known as anticipation) may result in symptom onset during childhood.

18 years of age is typically referred to as childhood-onset myotonic dystrophy (ChDM). However, alternate definitions designate further cut points depending on age of onset. ${ }^{6,7}$ Although the exact global prevalence is unknown, children with CDM likely represent $10 \%-30 \%$ of the overall DM1 population. ${ }^{4,8}$

These disorders cause significant morbidity and mortality. Children with CDM often require intensive intervention at birth because of hypotonia, respiratory failure, and feeding difficulties. ${ }^{4,9}$ For children with CDM ventilated longer than 3 months, there is a $30 \%$ mortality in the first year of life. ${ }^{10}$ Both children with CDM and ChDM may have symptoms associated with attention deficit hyperactivity disorder or autism spectrum disorder (sometimes referred to as social communication disorder) during childhood. ${ }^{11,12}$ They also have signifcant motor delays ${ }^{13}$ and may have intractable irritable bowel symptoms, including incontinence. Previous research suggests that $88 \%$ of individuals with congenital or childhood-onset myotonic dystrophy are unemployed over the age of 18 years. ${ }^{14}$

The multisystemic nature, morbidity, and mortality associated with congenital and childhood-onset myotonic dystrophy necessitate the development of care recommendations to standardize care. These consensus-based recommendations will also set the foundation for innovative clinical initiatives where gaps exist and also further research to improve aspects of management. These care recommendations may also better prepare the pediatric DM1 community for future clinical trials because variation in clinical care may have significant effects on the outcome of children participating in geographically dispersed clinical research sites.

\section{Methods}

\section{Participant recruitment}

The Myotonic Dystrophy Foundation recruited clinicians from the United States, Canada, and Europe who have experience in the treatment of children with DM1 to develop consensus-based recommendations.

\section{Consensus approach}

As previously described, the Myotonic Dystrophy Foundation developed a two-phase consensus building methodology using components of the single text procedure and nominal group technique. ${ }^{15}$ This approach was chosen given both the sparsity of literature surrounding many of the clinical aspects and the extensive experience of the clinicians in this area.
Three of the authors (N.E.J., C.C., and E.Z.) created the initial draft document, drawing from the existing literature and clinical practice that served as an initial text for the recommendation developments.

After creation of the single text, stakeholders were engaged to refine the recommendations through a consensus-based approach. The experts were initially assigned to specific areas of recommendations, where they refined the recommendations. A facilitator (LH) then lead a series of meetings to review, revise, and finalize the recommendations with the entire author panel.

These efforts led to the final consensus-based care recommendations along with a quick reference guide. The care recommendations are divided into 2 main sections, the General Care Considerations and Systems-based Approach to Management. Because there are differences between childhood-onset and congenital-onset DM1, recommendations specific to CDM are separated throughout the document. The Quick Reference Guide is provided as an appendix, and the full document is available online (appendix e-1, links.lww.com/CPJ/A89). Both feature flowcharts and other infographics for ease of use.

\section{Results}

See full recommendations at Neurology.org/cp.

\section{General care considerations}

\section{Diagnosis and classification}

- The diagnosis of DM1 should be suspected in any child with a family history of DM1 and/or presenting with one or more of the following features:

- Eyelid ptosis and/or oral motor weakness

- Distal weakness, primarily of the finger and wrist flexors, without contractures, or weakness of the neck flexors

- Myotonia or "stiffness" of muscles

- Autistic features or social communication difficulties

- Attention deficit disorder, anxiety, and other behavioral problems

- Developmental delay and/or Intellectual disability

The multisystemic nature, morbidity, and mortality associated with congenital and childhood-onset myotonic dystrophy necessitate the development of care recommendations to standardize and improve the care of this population. 
- Learning disabilities (e.g., dyslexia, dyscalculia)

- Excessive daytime sleepiness (EDS)

- Gastrointestinal issues: constipation or diarrhea

- Scoliosis

- Arrhythmia

- Prolonged recovery or respiratory arrest after anesthesia

- Neonatal features of hypotonia, weakness, club foot, respiratory distress, or feeding problems

- The classification of congenital and childhood-onset DM1 is provided in table 1 in Quick Reference Guide. Note that diagnosis may be made retrospectively after reviewing symptom onset. Fetal tissue with long CTG repeats should not be called CDM because this diagnosis is reserved for newborns. In these cases, we would suggest use of fetal DM1 as more appropriate.

- Genetic counseling is recommended for patients exhibiting clinical signs indicative of DM1, or have atrisk family members, to enable them to make an informed decision about whether to proceed to genetic testing. Individuals with 37-49 CTG repeats are deemed very unlikely to develop detectable DM1 symptoms. However, such "premutations" can expand into the disease range in subsequent generations, particularly when transmitted by women. Individuals thus identified should be offered genetic counseling (see Genetic counseling) to discuss their risk for transmitting DM1.

\section{Genetic counseling}

- Referral to genetic counseling (see nsgc.org) is recommended for all patients with congenital and childhoodonset DM1 and their parents and to assess the parents for the diagnosis of DM1.

- Genetic counseling in affected families should convey information about:

- The inheritance pattern of disease (autosomal dominant inheritance)

- The wide variability in the scope and severity of DM1 symptoms, even within the same family

- The possibility of changes in symptom scope and severity over time

- The likelihood that the mutation will expand and the disease will become more severe as it is passed from generation to generation (anticipation)

- Particular attention to the possibility of a minimally affected mother giving birth to a severely affected child

- Options for family planning

- Do not use CTG repeat numbers, if available, for genetic advice or prognostication; these need to be discussed with a genetic counselor. Specifically, repeat size may be an indicator of severity, but it does not provide any information about the prognosis.

\section{Focus on CDM}

- Once a family has had a child with CDM, there is an increased risk that the next affected child with DM1 is likely to have congenital form as well.

\section{Neonatal care}

- A high-risk obstetrician should provide prenatal obstetric care for mothers known or suspected to carry a child with DM1.

- Pediatric or neonatal specialist should be present at delivery if a mother is known to have DM1 or if the child is known or suspected to have DM1.

\section{Focus on CDM}

- Children with CDM will often need management in a neonatal intensive care unit with the capability to deal with breathing and feeding support. This team requires a range of neonatal and consulting specialists who can manage the genetic, respiratory, gastrointestinal, orthopedic, neuromuscular, neurosurgical, and cardiac issues. See figure 1 in Quick Reference Guide for neonatal care.

\section{End of life counseling and management}

- Recommend the introduction of palliative care at the time of diagnosis and at regular intervals thereafter. When a formal pediatric palliative care team is available, they should be consulted.

- Recognize and address caregiver burden, whether the caregiver has DM1, offering respite care or equivalent measures to patient to improve family support. Address normal grief on the part of the patient and family and offer counseling as appropriate.

- Establish an emergency health care plan and advance directives with the family.

\section{Focus on CDM}

- Introduce the concept that the natural history of the disease includes progressive improvement of strength for the first decade of life; however, the complications of $\mathrm{CDM}$ can be critical and have a high risk of mortality, particularly in the first year of life.

- Advise families or caregivers that invasive and noninvasive ventilation (NIV) and nutrition through gastrostomy tube are acceptable parts of care for patients with CDM.

\section{Surgery and anesthesia}

- Inform all caregivers that anyone administering an anesthetic should be aware of the DM1 diagnosis.

- When possible combine procedures under a single sedation.

- Arrange for a preanesthetic visit for all children planning to have deep sedation for a diagnostic test, procedure, or surgery. If possible, include a pulmonologist with expertise in neuromuscular diseases during this visit.

- Even if the patient has mild DM1, monitoring for a longer period of time than is typical following anesthesia or surgery will allow for identifying serious adverse events in the hospital setting.

- Providers are encouraged to review the Myotonic Dystrophy Foundation Practical Suggestions for the 
Anesthetic Management of a Myotonic Dystrophy Patient (myotonic.org/sites/default/files/MDF_LongForm_ AnesGuidelines_01C.pdf) for anesthesia risks and recommendations before any surgeries or procedures requiring anesthesia and the Anesthesia Quick Reference Guide (myotonic.org/sites/default/files/MDF Anesthesia Guidelines FNL 20162 2. pdf). These documents should be reviewed before treatment decisions.

\section{Focus on CDM}

- It is worth noting that children with CDM are at a higher risk of anesthetic complications, given the underlying respiratory involvement, as opposed to those with childhood-onset myotonic dystrophy.

\section{Systems-based approach to management}

\section{Respiratory}

- Signs of respiratory problems in children with myotonic dystrophy include ineffective cough, recurrent pulmonary infections, orthopnea, dyspnea, poor sleep, morning headaches, apnea, fatigue, and snoring.

- See figure 2 in Quick Reference Guide for a flowchart of testing and treatment options in congenital and childhood-onset myotonic dystrophy.

\section{Focus on CDM}

- For CDM children who remain on longer term trach ventilation, there is often improvement in respiratory strength over time, and consideration to decannulate a tracheostomy should be made after careful consideration with the multidisciplinary team including neurology; respirology; ear, nose, and throat; and the family. Consideration of airway control, respiratory infection frequency, ability to tolerate a facial or nasal mask for NIV and compliance and cooperation with maintenance pulmonary therapy such as cough assist, breathe staking, etc. Testing for hypoventilation in sleep should be done before decannulation.

\section{Cardiovascular}

- Inform families of the risks of arrhythmias and cardiac dysfunction and the importance of prompt medical attention if symptoms are observed (i.e., palpitations, presyncope, syncope, dyspnea, chest pain, unexplained fatigue).

- A 12-lead ECG should be performed at DM1 diagnosis, and if normal and the patient remains asymptomatic, ECG should be performed annually and warrants more investigation if the patient is symptomatic.

- If the ECG is normal and clinical suspicion is high, a 24-hour Holter monitor may be considered as a second-line investigation.

- Because specific medications such as mexiletine and psychostimulants are antiarrhythmic, an ECG before use, again within 3 months of starting therapy, and then at serial intervals is recommended.

- Consider in-hospital cardiac monitoring to detect arrhythmias if admitted for longer duration than typical after surgical procedures or if admitted due to severe illness or infection

- For young DM1 patients, serial exercise stress testing and signal-averaged ECGs may be considered.

- Evaluate and treat using American Heart Association (AHA) Management of Cardiac Involvement Associated With Neuromuscular Diseases A Scientific Statement From the American Heart Association 2017 circ.ahajournals. org/content/136/13/e200.long and ACC ([American College of Cardiology]/AHA)/ESC (European Society of Cardiology) Guidelines for Management of Patients with Ventricular Arrhythmias and the Prevention of Sudden Cardiac Death (see ncbi.nlm.nih.gov/pubmed/ 16949478)- section on pediatric issues 13.4.

\section{Skeletal muscle weakness, orthopedic complications, and rehabilitation}

- Children should be evaluated early and often for physical, occupational, and speech therapy needs with specific attention to:

- Feeding concerns and dysphagia

- Gross motor delay

- Gross and fine motor weakness

- Dysarthria and potential augmentative and alternative communication needs

- Language acquisition delays

- The spine should be assessed for scoliosis and, if necessary, consider bracing or referral to orthopedic surgeon.

- Children should be encouraged to participate in speech therapy targeting speech, language, and communication from a very early age.

\section{Focus on CDM}

- Newborns with CDM often having difficulty feeding and alternative nutrition should be considered. After about a year of actively working with a speech therapist or occupational therapist, most children can generally start on oral feeding.

- Children with CDM experience progressive improvement in their proximal strength until adolescence, at a minimum. Therefore, children should be encouraged to participate in physical activities.

- Prevention of joint contractures are key to management and should be closely monitored with early initiation of stretching. Treatment of talipes equinovarus and other joint contractures should include initial stretching regimen and appropriate ankle bracing (for talipes equinovarus). Serial casting may be considered.

\section{Skeletal muscle myotonia}

- Delayed relaxation after grip or percussion, difficulty related to activities of daily life, progressive speech 
impairment, or profound irritable bowel symptoms are signs often related to myotonia.

- Mexiletine (Mexitil) is an option for myotonia, if it is demonstrated and is distressing to the patient. Mexiletine may not be approved for use in every country. In these cases, other sodium channel antagonists may be considered.

- Because mexiletine is an antiarrhythmic, an ECG before use, again within 3 months of starting therapy, and then at serial intervals is recommended.

- Instruct the patient to avoid dyspepsia and transient "dizzy feelings" associated with mexiletine treatment by taking it with food to extend absorption and lower peak level in blood.

\section{Ocular and hearing management}

- Baseline audiometry should be performed, especially at school age.

- Ophthalmologic assessment should be performed at diagnosis and at least yearly to evaluate for hyperopia, stigmatism, strabismus, and visual acuity to prevent evolution of visual impairment.

- Eyelid ptosis; if ptosis becomes severe and interferes with vision, intervention such as eyelid "crutches" that can be inserted into glasses may be warranted. Try crutches as a remedy for ptosis before eyelid surgery is considered because of anesthesia risks. Ophthalmic lubricants for dry eye may be considered.

\section{Gastrointestinal and genitourinary management}

- Presence of gastrointestinal symptoms such as abdominal pain, constipation, fecal incontinence, or diarrhea may be a frequent problem. The symptoms may mimic irritable bowel syndrome (IBS). ${ }^{15}$ Fiber supplementation (more than $8 \mathrm{~g}$ daily) is the first-line treatment.

- Gentle laxatives (see below) for constipation. Oils should be avoided as they will lead to diarrhea. If a patient does not respond to the first- or second-line recommendations below, a referral to a gastrointestinal specialist for anal manometry should be considered:

- First-line therapy recommendations: polyethylene glycol (Miralax), senna (Ex-Lax, Senokot), docusate (Colace), or lactulose (Cholac)

- Second-line therapy recommendations: bisacodyl (Dulcolax, Correctol), lubiprostone (Amitiza), or linaclotide (Linzess)

- Metoclopramide (Reglan) may be used to reduce the symptoms of gastroparesis, pseudo-obstruction, and gastric reflux. Providers should be aware of the risk of acute dystonic reactions with this medication. Longterm use is not recommended because this drug can cause tardive dyskinesia.

- Cholestyramine and loperamide are other options in the presence of mainly diarrhea and anticholinergic drug such as hyoscyamine sulfate in the presence of IBS. Because anticholinergic drugs may be antiarrhythmic, see Cardiac section on management.
- Mexiletine may be considered for refractory diarrhea or constipation because the drug may be antiarrhythmic, see Cardiac section on management.

- If bacterial overgrowth is found on breath testing, treating with antibiotics may reduce diarrhea.

\section{Focus on CDM}

- As mentioned in the neonatal care section, children with CDM may require a temporary feeding tube. If dysphagia persists, consider enteral nutrition. Refer to speech therapy. Children should be periodically re-assessed for improving dysphagia.

- Children with CDM often benefit from dysphagia therapy. With aggressive dysphagia therapy, children with CDM often are able to feed orally within the first year of life.

\section{Neurodevelopmental management Recommendations}

- Neuropsychological testing should be performed in every child with DM1 to delineate cognitive strengths and weaknesses. This may include the following:

- Psychometric assessment of global intellectual ability and adaptive functioning

- Assessment of executive functions

- Assessment of social cognition

- Assessment of visuomotor integration and visuospatial ability

- Assessment of receptive and expressive language abilities

- Assessment of EDS

- Assessment of learning disabilities (specific tests for dyscalculia, dyslexia, and dyspraxia)

- The assessments should be performed in the congenital form in preschool age and should be repeated, depending on the level of functioning, 2-3 times before adulthood. In childhood DM1, neuropsychological testing is recommended at diagnosis and repeated in preschool or school age and college period.

- Patients with psychiatric or behavioral issues should be referred to a mental health care professional for assessment of Autism Spectrum Disorders, Attention Deficit disorders with or without Hyperactivity, alexiythmia, and other behavioral problems.

- Psychostimulants may be beneficial if attention deficits are associated with an impairing level of fatigue or EDS (see excessive daytime sleepiness). As psychostimulants may be proarrhythmic, see Cardiac section on stimulant management:

- Serotonin-enhancing antidepressants if excessive anxiety or other treatable psychiatric symptoms are present

- Specific cognitive remediation programs to enhance social emotional abilities (visual contact, joint attention, emotional regulation) or executive functions efficiency (inhibitory control, attention, working memory, and cognitive flexibility) using dedicated software (e.g., Cogmed ${ }^{\circledR}$ )

- Language remediation and reading therapy should be considered because of the presence of cognitive deficits, even in children with normal intelligence. Attention deficit, 
fatigability, and visual-spatial construction dysfunction can result in specific learning disorders with impairment in reading and spelling as well as in mathematics.

\section{Psychosocial management}

- Healthcare professionals have a responsibility to coordinate specialist care and support services for children with DM1. There is a need to be alert to the psychological and social dysfunctions and monitor home and educational circumstances. Liaison between agencies is essential to ensure a consistent approach between health, education, and social care agencies.

- Children with DM1 should have access to appropriate psychological and therapy services at an early age to ensure they are fulfilling their maximum potential and learning coping strategies for later life. The modification of activities including social engagement strategies would provide a foundation for each child to grow in confidence and esteem.

- Family care and support is essential throughout childhood with support and social care assistance where required. Schools should be provided with specialist information about the care and management of a child with DM1. A social work consult or a referral to nursing case management can also be beneficial for patients. A holistic approach is critical because the affected parent may also need additional assistance.

- Families should have access to disability benefits, adequate housing and adaptations during the progression of the condition.

\section{Excessive daytime sleepiness}

- Family members and educators should be educated about the EDS that comes with DM1.

- Children should be screened for signs of EDS, including prolonged naps or falling asleep in school.

- Possible sleep apnea should be evaluated with overnight oximetry or polysomnogram.

- Positive-pressure ventilation can be considered if a DM1 patient's sleepiness is thought to be related to nocturnal or daytime hypoventilation or sleep apnea. Patients should be referred to pulmonologists who have experience in neuromuscular diseases for consideration of assisted ventilation.

- Stimulant therapy with a psychostimulant such as modafinil (Provigil), methylphenidate, or other stimulant can be considered if central hypersomnia is suspected. Often difficulty staying awake in school is a triggering factor. Special care should be taken in children with previously detected cardiac arrhythmia (See Cardiac section on stimulant management).

\section{Endocrine and metabolism}

- DM1 male patients should undergo a detailed physical examination in search of gonadal atrophy or cryptorchidism.

- Patients should have a HbAlc and thyroid-stimulating hormone and Free T4 level measured at baseline and every 3 years, or if there is a clinical suspicion.
- Adolescent patients should be screened as adult patients:

- Gonadal insufficiency and complications of the reproductive system: Inquiring about amenorrhea or dysmenorrhea for the female patients, and erectile dysfunction for male patients

- Fasting blood lipids, plasma glucose, liver enzymes, bilirubin levels, and gamma-glutamyl transpeptidase should be measured at baseline.

\section{Conclusions}

The recommendations for care of congenital and childhoodonset myotonic dystrophy have been created by consensus of clinicians experienced in their care management. Given the absence of rigorous studies in many of these areas, these guidelines were created by consensus. They are designed to standardize the care of children with a multisystemic disorder that leads to significant morbidity and mortality.

\section{Study funding}

Myotonic Dystrophy Foundation.

\section{Disclosure}

N. Johnson serves on the scientific advisory boards of Cytokinetics, AveXis, AMO Pharma, and Biogen Idec; has received funding for travel and/or speaker honoraria from Strongbridge; serves as a consultant for AMO Pharma, AveXis, and Vertex Pharma; and receives research support from Ionis Pharmaceuticals, Biogen Idec, Valerion Therapeutics, Cytokinetics, Acceleron, AveXis, AMO Pharma, NIH/NINDS, FDA, Muscular Dystrophy Association, and Myotonic Dystrophy Foundation. E.Z. Aldana and N. Angeard report no disclosures. T. Ashizawa serves on scientific advisory boards for the Myotonic Dystrophy Foundation, NIH, and National Ataxia Foundation; has received funding for travel from Biohaven, PacBio, and NIH; receives research support from Myotonic Dystrophy Foundation, National Ataxia Foundation, Biohaven Pharmaceuticals, Biogen, and NIH/NINDS; and is a professor at Weill Cornell Medical College, adjunct professor at Baylor College of Medicine, guest faculty at Central South University, China. K.N. Berggren serves on the scientific advisory board of Biogen and receives funding for travel and/or speaker honoraria from HDSA and FSH Society. C. MariniBettolo has served on the scientific advisory boards of Avexis and Biogen. T. Duong, A.-B. Ekström, V. Sansone, C. Tian, and L. Hellerstein report no disclosures. C. Campbell serves on the scientific advisory boards of Catabasis and PTC Therapeutics and receives research support from Valerion Pharmaceuticals, PTC Therapeutics, Pfizer, Ionis, Eli Lilly, Prosensa, Child Health Foundation, and Jesse's Journey Foundation. Full disclosure form information provided by the authors is available with the full text of this article at Neurology.org/cp.

\section{Publication history}

Received by Neurology: Clinical Practice December 21, 2018. Accepted in final form March 4, 2019. 
Appendix Authors

\begin{tabular}{|c|c|c|c|}
\hline Name & Location & Role & Contribution \\
\hline $\begin{array}{l}\text { Nicholas E. } \\
\text { Johnson, MD, } \\
\text { MCSI }\end{array}$ & $\begin{array}{l}\text { Virginia } \\
\text { Commonwealth } \\
\text { University, Virginia }\end{array}$ & Author & $\begin{array}{l}\text { Data acquisition, } \\
\text { drafting and } \\
\text { revision of the } \\
\text { manuscript, } \\
\text { publication of the } \\
\text { draft and revision }\end{array}$ \\
\hline $\begin{array}{l}\text { Eugenio } \\
\text { Zapata } \\
\text { Aldana, MD }\end{array}$ & $\begin{array}{l}\text { University of } \\
\text { Western Ontario, } \\
\text { Ontario, Canada }\end{array}$ & Author & $\begin{array}{l}\text { Data acquisition, } \\
\text { drafting and } \\
\text { revision of the } \\
\text { manuscript }\end{array}$ \\
\hline $\begin{array}{l}\text { Nathalie } \\
\text { Angeard, PhD }\end{array}$ & $\begin{array}{l}\text { Inserm \& } \\
\text { University of Paris } \\
\text { Descartes, Paris, } \\
\text { France }\end{array}$ & Author & $\begin{array}{l}\text { Data acquisition, } \\
\text { drafting and } \\
\text { revision of the } \\
\text { manuscript }\end{array}$ \\
\hline $\begin{array}{l}\text { Tetsuo } \\
\text { Ashizawa, MD }\end{array}$ & $\begin{array}{l}\text { Houston } \\
\text { Methodist } \\
\text { Neurological } \\
\text { Institute, Texas }\end{array}$ & Author & $\begin{array}{l}\text { Data acquisition, } \\
\text { drafting and } \\
\text { revision of the } \\
\text { manuscript }\end{array}$ \\
\hline $\begin{array}{l}\text { Kiera N } \\
\text { Berggren, MA/ } \\
\text { CCC-SLP, MS }\end{array}$ & $\begin{array}{l}\text { Virginia } \\
\text { Commonwealth } \\
\text { University, Virginia }\end{array}$ & Author & $\begin{array}{l}\text { Data acquisition, } \\
\text { drafting and } \\
\text { revision of the } \\
\text { manuscript }\end{array}$ \\
\hline $\begin{array}{l}\text { Chiara Marini- } \\
\text { Bettolo, MD, } \\
\text { PhD }\end{array}$ & $\begin{array}{l}\text { Institute of Genetic } \\
\text { Medicine, } \\
\text { Newcastle } \\
\text { University and } \\
\text { Newcastle upon } \\
\text { Tyne Hospitals } \\
\text { NHS Foundation } \\
\text { Trust, Newcastle } \\
\text { upon Tyne, UK }\end{array}$ & Author & $\begin{array}{l}\text { Data acquisition, } \\
\text { drafting and } \\
\text { revision of the } \\
\text { manuscript }\end{array}$ \\
\hline
\end{tabular}

Appendix (continued)

\begin{tabular}{|c|c|c|c|}
\hline Name & Location & Role & Contribution \\
\hline $\begin{array}{l}\text { Tina Duong, } \\
\text { MPT, PhD }\end{array}$ & $\begin{array}{l}\text { Stanford } \\
\text { University, CA }\end{array}$ & Author & $\begin{array}{l}\text { Data acquisition, } \\
\text { drafting and } \\
\text { revision of the } \\
\text { manuscript }\end{array}$ \\
\hline $\begin{array}{l}\text { Anne-Berit } \\
\text { Ekström, MD, } \\
\text { PhD }\end{array}$ & $\begin{array}{l}\text { Queen Silvia } \\
\text { Children's } \\
\text { Hospital, } \\
\text { Gothenburg, } \\
\text { Sweden }\end{array}$ & Author & $\begin{array}{l}\text { Data acquisition, } \\
\text { drafting and } \\
\text { revision of the } \\
\text { manuscript }\end{array}$ \\
\hline $\begin{array}{l}\text { Valeria } \\
\text { Sansone, MD }\end{array}$ & $\begin{array}{l}\text { NEMO Clinic, } \\
\text { Milan, Italy }\end{array}$ & Author & $\begin{array}{l}\text { Data acquisition, } \\
\text { drafting and } \\
\text { revision of the } \\
\text { manuscript }\end{array}$ \\
\hline $\begin{array}{l}\text { Cuixia Tian, } \\
\text { MD }\end{array}$ & $\begin{array}{l}\text { Cincinnati } \\
\text { Children's Hospital } \\
\text { Medical Center, } \\
\text { Cincinnati, OH }\end{array}$ & Author & $\begin{array}{l}\text { Data acquisition, } \\
\text { drafting and } \\
\text { revision of the } \\
\text { manuscript }\end{array}$ \\
\hline $\begin{array}{l}\text { Leah } \\
\text { Hellerstein, } \\
\text { LCSW, MPH }\end{array}$ & $\begin{array}{l}\text { Myotonic } \\
\text { Dystrophy } \\
\text { Foundation, San } \\
\text { Francisco, CA }\end{array}$ & $\begin{array}{l}\text { Corresponding } \\
\text { Author }\end{array}$ & $\begin{array}{l}\text { Obtaining funding, } \\
\text { drafting and } \\
\text { reviewing the } \\
\text { manuscript, study } \\
\text { concept and } \\
\text { design }\end{array}$ \\
\hline $\begin{array}{l}\text { Craig } \\
\text { Campbell, MD }\end{array}$ & $\begin{array}{l}\text { University of } \\
\text { Western Ontario, } \\
\text { Ontario, Canada }\end{array}$ & Author & $\begin{array}{l}\text { Data acquisition, } \\
\text { drafting and } \\
\text { revision of the } \\
\text { manuscript }\end{array}$ \\
\hline
\end{tabular}




\section{Consensus-based Care Recommendations for Congenital \& Childhood-onset Myotonic Dystrophy Type I Quick Reference Version}

The Myotonic Dystrophy Foundation recruited clinicians from the United States, Canada, \& Europe who have experience in the treatment of children with myotonic dystrophy type I (DM1) to develop consensus-based recommendations. See full recommendations at www.myotonic.org/

\section{RECOMMENDATIONS}

\section{Diagnosis \& classification}

- The diagnosis of DM1 should be suspected in any child with a family history of DM1 \&/or presenting with one or more of the following features:

- Eyelid ptosis \&/or oral motor weakness

- Distal weakness, primarily of the finger \& wrist flexors, without contractures, or weakness of the neck flexors

- Myotonia or "stiffness" of muscles

- Autistic features or social communication difficulties

- Attention deficit disorder, anxiety \& other behavioral problems

- Developmental delay \&/or Intellectual disability

- Learning disabilities (e.g. dyslexia, dyscalculia)

- Excessive daytime sleepiness

- Gastrointestinal issues: constipation or diarrhea

- Scoliosis

- Arrhythmia

- Prolonged recovery or respiratory arrest following anesthesia

- Neonatal features of hypotonia, weakness, club foot, respiratory distress or feeding problems

- The classification of congenital \& childhood-onset DM1 is provided in Table 1. Note that diagnosis may be made retrospectively after reviewing symptom onset. Fetal tissue with long CTG repeats should not be called CDM as this diagnosis is reserved for newborns. In these cases, we would suggest use of fetal DM1 as more appropriate

\section{Genetic counseling}

- Genetic counseling in affected families should convey information about:

- The inheritance pattern of disease (autosomal dominant inheritance)

- The wide variability in the scope \& severity of DM1 symptoms, even within the same family

- The possibility of changes in symptom scope \& severity over time

- The likelihood that the mutation will expand $\&$ the disease will become more severe as it is passed from generation to generation (anticipation)

- Particular attention to the possibility of a minimally-affected mother giving birth to a severely affected child

- Options for family planning

- Do not use CTG repeat numbers, if available, for genetic advice or prognostication; these need to be discussed with a genetic counselor. Specifically, repeat size may be an indicator of severity, but it does not provide any information about the prognosis
Table 1. Classification of Congenital \& Childhoodonset Myotonic Dystrophy

Congenital myotonic dystrophy

- Physical signs or symptoms attributable to DM1 in the pre\&/or perinatal period:

- Reduced fetal movement

- Polyhydramnios

- Respiratory failure

- Feeding problems

- Weakness \& hypotonia

- Talipes \&/or other contractures

- Need for medical intervention or hospitalization

- Generic confirmation of expanded CTG repeat size

Childhood myotonic dystrophy

- Symptoms attributed to myotonic dystrophy prior to age 18 years

- Genetic confirmation of expanded CTG repeat size

- Some classification systems further divide this group into a childhood form with symptoms $<10$ years \& a juvenile form with symptoms between $10 \& 18$ years

\section{Focus on CDM}

- Once a family has had a child with CDM, there is an increased risk that the next affected child with DM1 is likely to have congenital form as well

\section{Neonatal care}

- A high-risk obstetrician should provide prenatal obstetric care for mothers known or suspected to carry a child with DM1

- Pediatric or neonatal specialist should be present at delivery if a mother is known to have DM1, or if the child is known or suspected to have DM1

\section{Focus on CDM}

- Children with CDM will often need management in a NICU with the capability to deal with breathing \& feeding support, \& that has a range of neonatal $\&$ consulting specialists who can manage genetic, respiratory, Gl, orthopedic, neuromuscular, neurosurgical, \& cardiac issues. See Figure 1 for neonatal care

\section{End of life counseling \& management}

- Recommend the introduction of palliative care at the time of diagnosis \& at regular intervals thereafter. When a formal pediatric palliative care team is available they should be consulted 


\section{Focus on CDM}

- Introduce the concept that the natural history of the disease is one of progressive muscle strength improvement, however the complications of CDM can be critical \& have a high risk of mortality, particularly in the first year of life

- Advise families or caregivers that invasive \& noninvasive ventilation, \& nutrition via gastrostomy tube are acceptable parts of care for patients with CDM

\section{Surgery \& anesthesia}

- Educate all caregivers that anyone administering an anesthetic should be aware of the DM1 diagnosis

- When possible combine procedures under a single sedation

- $\quad$ Arrange for a pre-anesthetic visit for all children planning to have deep sedation for a diagnostic test, procedure or surgery. If possible, include a pulmonologist with expertise in neuromuscular diseases during this visit

See Myotonic Dystrophy Foundation Practical Suggestions for the Anesthetic Management of a Myotonic Dystrophy Patient (http://www.myotonic.org/sites/default/files/MDF_LongForm_ AnesGuidelines_01C.pdf) for anesthesia risks \& recommendations before any surgeries or procedures requiring anesthesia $\&$ the Anesthesia Quick Reference Guide

\section{Focus on CDM}

- It is worth noting that children with CDM are at a higher risk of anesthetic complications given the underlying respiratory involvement as opposed to those with childhood onset

\section{SYSTEMS-BASED \\ CARE RECOMMENDATIONS}

\section{Respiratory}

- $\quad$ Signs of respiratory problems in children with myotonic dystrophy include ineffective cough, recurrent pulmonary infections, orthopnea, dyspnea, poor sleep, morning headaches, apnea, fatigue \& snoring

\section{Focus on CDM}

- For CDM children who remain on longer term trach ventilation there is often improvement in respiratory strength over time \& consideration to decannulate a tracheostomy should be made after careful consideration with the multidisciplinary team including neurology, respirology, ENT, \& the family. Consideration of airway control, respiratory infection frequency, ability to tolerate a facial or nasal mask for NIV \& compliance $\&$ cooperation with maintenance pulmonary therapy such as cough assist, breath staking etc. Testing for hypoventilation in sleep should be done prior to decannulation

- Cardiovascular

- Inform families of the risks of arrhythmias \& cardiac dysfunction $\&$ the importance of prompt medical attention if symptoms are observed (i.e. palpitations, pre-syncope, syncope, dyspnea, chest pain, unexplained fatigue)

- $\quad$ A 12-lead ECG should be performed at DM1 diagnosis, if normal \& the patient remains asymptomatic, ECG should be performed annually \& warrants more investigation if the patient is symptomatic

- $\quad$ As specific medications such as mexiletine \& psychostimulants are antiarrhythmic, an electrocardiogram (ECG) prior to use, again within three months of starting therapy, \& then at serial intervals is recommended
- $\quad$ Consider in-hospital cardiac monitoring to detect arrhythmias if admitted for longer duration than typical following surgical procedures or if admitted due to severe illness or infection

- $\quad$ Evaluate \& treat using American Heart Association AHA Management of Cardiac Involvement Associated With Neuromuscular Diseases: A Scientific Statement From the American Heart Association 2017 http://circ.ahajournals. org/content/136/13/e200.long \& ACC [American College of Cardiology]/AHA [American Heart Association)]/ ESC [European Society of Cardiology] Guidelines for Management of Patients with Ventricular Arrhythmias \& the Prevention of Sudden Cardiac Death (see http://www.ncbi. nlm.nih.gov/pubmed/16949478)- section on pediatric issues 13.4

\section{Skeletal muscle weakness, orthopedic} complications, \& rehabilitation

- $\quad$ Children should be evaluated early \& often for physical, occupational, \& speech therapy needs with specific attention to:

- $\quad$ Feeding concerns \& dysphagia

- Gross motor delay

- Gross \& fine motor weakness

- Dysarthria \& potential augmentative \& alternative communication (AAC) needs

- Language acquisition delays

- The spine should be assessed for scoliosis \&, if necessary, consider bracing or referral to orthopedic surgeon

- Children should be encouraged to participate in speech therapy targeting speech, language, \& communication from a very early age

\section{Focus on CDM}

- $\quad$ Newborns with CDM often having difficulty feeding \& alternative nutrition should be considered. After about a year of actively working with a speech therapist or occupational therapist, most children can generally start on oral feeding

- $\quad$ Children with CDM experience progressive improvement in their proximal strength until adolescence, at a minimum. Therefore, children should be encouraged to participate in physical activity

- $\quad$ Prevention of joint contractures are key to management \& should be closely monitored with early initiation of stretching. Treatment of talipes equinovarus \& other joint contractures should include initial stretching regiment $\&$ appropriate ankle bracing (for talipes equinovarus). Serial casting may be considered

\section{Skeletal muscle myotonia}

- Mexiletine (Mexitil) is an option for myotonia, if it is demonstrated \& is distressing to the patient

- As mexiletine is an antiarrhythmic, an electrocardiogram (ECG) prior to use, again within three months of starting therapy, \& then at serial intervals is recommended

\section{Ocular \& hearing management}

- Baseline audiometry should be performed, especially at school age

- Ophthalmological assessment at diagnosis \& on a regularly, at least yearly, basis regarding hyperopia, astigmatism, strabismus $\&$ visual acuity to prevent evolvement of visual impairment

- Eyelid ptosis; if ptosis becomes severe \& interferes with vision, intervention such as eyelid "crutches" that can be inserted into glasses may be warranted. Try crutches as a remedy for ptosis before eyelid surgery is considered, due to anesthesia risks. Ophthalmic lubricants for dry eye may be considered 
Gastrointestinal \& genitourinary management

- Presence of gastrointestinal symptoms such as abdominal pain, constipation, fecal incontinence or diarrhea may be a frequent problem. The symptoms may mimic irritable bowel syndrome IBS. Fiber supplementation (more than 8 grams daily) is the first line treatment

- Gentle laxatives (see below) for constipation. Oils should be avoided. If a patient does not respond to the first- or secondline recommendations below, a referral to a gastrointestinal specialist for anal manometry should be considered:

- First-line therapy recommendations: polyethylene glycol (Miralax), senna (Ex-Lax, Senokot), docusate (Colace) or lactulose (Cholac)

- Second-line therapy recommendations: bisacodyl (Dulcolax, Correctol), lubiprostone (Amitiza) or linaclotide (Linzess)

- Metoclopramide (Reglan) may be used to reduce the symptoms of gastroparesis, pseudo-obstruction \& gastric reflux. Long-term use is not recommended because this drug can cause tardive dyskinesia

- Cholestyramine \& loperamide are other options in presence of mainly diarrhea \& anticholinergic drug such as hyoscyamine sulfate in presence of IBS. As anticholinergic drugs may be antiarrhythmic, see Cardiac section on management

- Mexiletine may be considered for refractory diarrhea or constipation, as the drug may be antiarrhythmic, see Cardiac section on management

- If bacterial overgrowth is found on breath testing, treating with antibiotics may reduce diarrhea

\section{Focus on CDM}

- As mentioned in the neonatal care section, children with CDM may require a temporary feeding tube. If dysphagia persists, consider enteral nutrition. Refer to speech therapy. Children should be periodically re-assessed for improving dysphagia

- $\quad$ Children with CDM often benefit from dysphagia therapy. With aggressive dysphagia therapy, children with CDM often are able to feed orally within the first year of life

\section{Endocrine \& metabolic}

- DM1 male patients should undergo a detailed physical examination in search of gonadal atrophy or cryptorchidism

- Patients should have a HbA1c \& thyroid stimulating hormone (TSH) \& FreeT4 level measured at baseline \& every 3 years, or if there is a clinical suspicion

\section{NEURODEVELOPMENTAL} CARE RECOMMENDATIONS

\section{Recommendations (SeeTable 2)}

- Neuropsychological testing should be performed in every child with DM1 to delineate cognitive strengths \& weaknesses. This may include:

- $\quad$ Psychometric assessment of global intellectual ability \& adaptive functioning

- Assessment of executive functions

- Assessment of social cognition

- Assessment of visuomotor integration \& visuospatial ability

- Assessment of receptive \& expressive language abilities

- Assessment of excessive daytime sleepiness
Table 2. Neurodevelopmental Management in DM

Cognitive \& psychometric tests should be performed at diagnosis, preschool, \& 2-3 more times before adulthood

\begin{tabular}{|c|c|}
\hline Domain/symptom assessed & Potential treatment \\
\hline $\begin{array}{l}\text { Global intellectual ability \& } \\
\text { adaptive function }\end{array}$ & $\begin{array}{l}\text { Serotonin-enhancing } \\
\text { antidepressants if excessive } \\
\text { anxiety or other treatable } \\
\text { psychiatric symptoms } \\
\text { present }\end{array}$ \\
\hline Social cognition & $\begin{array}{l}\text { Remediation programs to } \\
\text { enhance social emotional } \\
\text { abilities (visual contact, } \\
\text { joint attention, emotional } \\
\text { regulation) }\end{array}$ \\
\hline Executive function & $\begin{array}{l}\text { Cognitive remediation } \\
\text { programs to enhance } \\
\text { executive efficiency } \\
\text { (impulsivity, attention, } \\
\text { working memory, \& mental } \\
\text { flexibility) using dedicated } \\
\text { software (e.g., Cogmed } ® \text { ) }\end{array}$ \\
\hline $\begin{array}{l}\text { Visuomotor integration \& visual } \\
\text { spatial ability }\end{array}$ & $\begin{array}{l}\text { Specific remediation } \\
\text { programs }\end{array}$ \\
\hline $\begin{array}{l}\text { Learning disabilities (specific } \\
\text { tests for dyscalculia, dyslexia, \& } \\
\text { dyspraxia) }\end{array}$ & $\begin{array}{l}\text { Language remediation \& } \\
\text { reading therapy }\end{array}$ \\
\hline Excessive daytime sleepiness & $\begin{array}{l}\text { Psychostimulants if } \\
\text { attention deficits are } \\
\text { associated with an impairing } \\
\text { level of fatigue or excessive } \\
\text { daytime sleepiness }\end{array}$ \\
\hline $\begin{array}{l}\text { Autism spectrum disorder, } \\
\text { attention deficit disorder }\end{array}$ & $\begin{array}{l}\text { Refer to mental health } \\
\text { professional }\end{array}$ \\
\hline
\end{tabular}

- Assessment of learning disabilities (specific tests for dyscalculia, dyslexia \& dyspraxia)

- The assessments should be performed in the congenital form in preschool age \& should be repeated, depending on the level of functioning, 2-3 times before adulthood. In childhood DM1 neuropsychological testing is recommended at diagnosis \& repeated in preschool or school age \& college period

- Patients with psychiatric or behavioral issues should be referred to a mental health care professional for assessment of autism spectrum disorders, attention deficit disorders with or without hyperactivity, alexythimia \& other behavioral problems

- Psychostimulants if attention deficits are associated with an impairing level of fatigue or excessive daytime sleepiness (see Excessive daytime sleepiness). As psychostimulants may be antiarrhythmic, see Cardiac section on stimulant management

- Serotonin-enhancing antidepressants if excessive anxiety or other treatable psychiatric symptoms are present

- Specific cognitive remediation programs to enhance social emotional abilities (visual contact, joint attention, emotional regulation) or executive functions efficiency (inhibitory control, attention, working memory, \& cognitive flexibility) using dedicated software (e.g., Cogmed $\left.{ }^{\circledR}\right)$ 


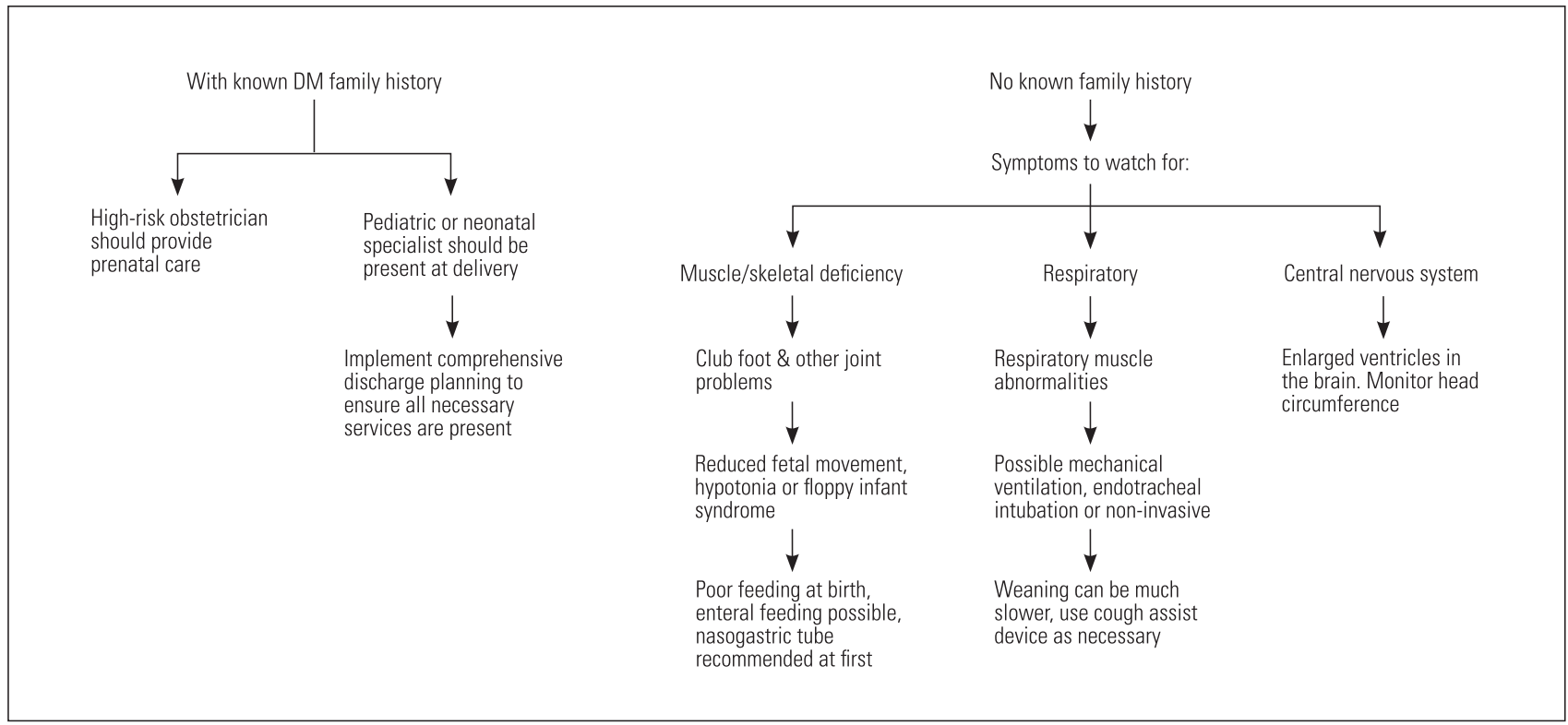

- Language remediation \& reading therapy should be considered due to the presence of cognitive deficits, even in children with normal intelligence. Attention deficit, fatigability, \& visualspatial construction dysfunction, can result in specific learning disorders with impairment in reading \& spelling as well as in mathematics

\section{Psychosocial management}

- Children with DM1 should have access to appropriate psychological \& therapy services at an early age to ensure they are fulfilling their maximum potential \& learning coping strategies for later life. The modification of activities including social engagement strategies would provide a foundation for each child to grow in confidence \& esteem

\section{Excessive daytime sleepiness}

- Children should be screened for signs of EDS, including prolonged naps, or falling asleep in school

- Possible sleep apnea should be evaluated with overnight oximetry or polysomnogram

- Positive-pressure ventilation can be considered if a DM1 patient's sleepiness is thought to be related to nocturnal or daytime hypoventilation or sleep apnea. Patients should be referred to pulmonologists who have experience in neuromuscular diseases for consideration of assisted ventilation

- Stimulant therapy with a psychostimulant such as modafinil (Provigil), methylphenidate, or other stimulant can be considered if central hypersomnia is suspected. Often difficulty staying awake in school is a triggering factor. Special care should be taken in children with previously detected cardiac arrhythmia. (See Cardiac section on stimulant management)

\section{Acknowledgments}

This project would not have been possible without the tireless \& longterm commitment made by the 11 international professionals involved in development. They included:

Eugenio Zapata Aldana, M.D. University of Western Ontario

Nathalie Angeard, Ph.D.

Inserm \& University of Paris Descartes

Tetsuo Ashizawa, M.D.

Houston Methodist Neurological Institute

Kiera Berggren, MA/CCC-SLP, MS

Virginia Commonwealth University
Craig Campbell, M.D.

University of Western Ontario

Tina Duong, MPT, Ph.D.

Stanford University

Anne-Berit Ekström, M.D., Ph.D. Queen Silvia Children's Hospital

Nicholas Johnson, M.D., MSCI

Virginia Commonwealth University
Chiara Marini-Bettolo, M.D., Ph.D. Newcastle University

Valeria Sansone, M.D. NEMO Clinic

CuixiaTian, M.D.

Cincinnati Children's Hospital Medical Center

A full list of authors \& an overview of the methodology used to develop consensus for these recommendations can be found here: http://www.myotonic.org/clinical-resources 


\section{References}

1. Fu YH, Pizzuti A, Fenwick RG Jr, et al. An unstable triplet repeat in a gene related to myotonic muscular dystrophy. Science 1992;255:1256-1258.

2. Brook JD, McCurrach ME, Harley HG, et al. Molecular basis of myotonic dystrophy: expansion of a trinucleotide (CTG) repeat at the 3 ' end of a transcript encoding a protein kinase family member. Cell 1992;68:799-808.

3. Mahadevan M, Tsilfidis C, Sabourin L, et al. Myotonic dystrophy mutation: an unstable CTG repeat in the 3' untranslated region of the gene. Science 1992;255:1253-1255.

4. Harper PS. Myotonic Dystrophy, 3rd ed. London: W.B. Saunders; 2001.

5. Bugiardini E, Meola G; DM-CNS Group. Consensus on cerebral involvement in myotonic dystrophy. Neuromuscul Disord 2014;24:445-452.

6. Koch MC, Grimm T, Harley HG, Harper PS. Genetic risks for children of women with myotonic dystrophy. Am J Hum Genet 1991;48:1084-1091.

7. Gagnon C, Heatwole C, Hébert LJ, et al. Report of the third outcome measures in myotonic dystrophy type 1 (OMMYD-3) international workshop Paris, France, June 8, 2015. J Neuromuscul Dis 2018;5:523-537.

8. Johnson NE, Hung M, Nasser E, et al. The impact of pregnancy on myotonic dystrophy: a registry-based study. J Neuromuscul Dis 2015;2:447-452.
9. Campbell C, Levin S, Siu VM, et al. Congenital myotonic dystrophy: Canadian population-based surveillance study. J Pediatr 2013;163:120-123.

10. Campbell C, Sherlock R, Jacob P, Blayney M. Congenital myotonic dystrophy: assisted ventilation duration and outcome. Pediatrics 2004;113:811-816.

11. Angeard N, Gargiulo M, Jacquette A, et al. Cognitive profile in childhood myotonic dystrophy type 1: is there a global impairment? Neuromuscul Disord 2007;17: 451-458.

12. Ekstrom AB, Hakenas-Plate L, Tulinius M, Wentz E. Cognition and adaptive skills in myotonic dystrophy type 1 : a study of 55 individuals with congenital and childhood forms. Dev Med Child Neurol 2009;51:982-990.

13. Kroksmark AK, Ekström AB, Björck E, Tulinius M. Myotonic dystrophy: muscle involvement in relation to disease type and size of expanded CTG-repeat sequence. Dev Med Child Neurol 2005;47:478-485.

14. Johnson NE, Ekstrom AB, Campbell C, et al. Parent-reported multi-national study of the impact of congenital and childhood onset myotonic dystrophy. Dev Med Child Neurol 2016;58:698-705.

15. Yao X, Yang YS, Cui LH, et al. Subtypes of irritable bowel syndrome on Rome III criteria: a multicenter study. J Gastroenterol Hepatol 2012;27:760-765.

\section{Share Your Insights, Expertise, and Experiences}

- How are you employing drugs and devices in your field?

- What ethical challenges do you face?

- Do you have a case report that is illustrative of a clinical challenge?

- What challenges have you faced or successes have you enjoyed in bringing greater efficiency to your practice?

Deliver a high-quality, peer-reviewed message to your colleagues in practice, submit your paper at NPub.org/NCP/submit. 


\title{
Neurology ${ }^{\circ}$ Clinical Practice
}

\section{Consensus-based care recommendations for congenital and childhood-onset myotonic dystrophy type 1}

Nicholas E. Johnson, Eugenio Zapata Aldana, Nathalie Angeard, et al.

Neurol Clin Pract 2019;9;443-454 Published Online before print April 24, 2019

DOI 10.1212/CPJ.0000000000000646

This information is current as of April 24, 2019

\begin{abstract}
Updated Information \&
Services

including high resolution figures, can be found at:

http://cp.neurology.org/content/9/5/443.full.html

References

This article cites 14 articles, 2 of which you can access for free at: http://cp.neurology.org/content/9/5/443.full.html\#\#ref-list-1

Citations

This article has been cited by 2 HighWire-hosted articles:

http://cp.neurology.org/content/9/5/443.full.html\#\#otherarticles

Subspecialty Collections

This article, along with others on similar topics, appears in the following collection(s):

All Neuromuscular Disease

http://cp.neurology.org//cgi/collection/all_neuromuscular_disease

All Pediatric

http://cp.neurology.org//cgi/collection/all_pediatric

Developmental disorders

http://cp.neurology.org//cgi/collection/developmental_disorders

Permissions \& Licensing

Information about reproducing this article in parts (figures,tables) or in its entirety can be found online at:

http://cp.neurology.org/misc/about.xhtml\#permissions

Reprints

Information about ordering reprints can be found online:

http://cp.neurology.org/misc/addir.xhtml\#reprintsus
\end{abstract}

Neurol Clin Pract is an official journal of the American Academy of Neurology. Published continuously since 2011, it is now a bimonthly with 6 issues per year. Copyright Copyright $\odot 2019$ The Author(s). Published by Wolters Kluwer Health, Inc. on behalf of the American Academy of Neurology.. All rights reserved. Print ISSN: 2163-0402. Online ISSN: 2163-0933.

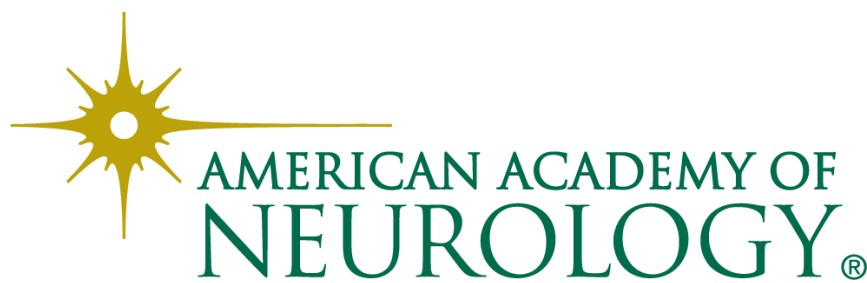

